\title{
Tendências atuais da pesquisa brasileira em Educação Física Parte 2: a heterogeneidade epistemológica nos programas de pós-graduação
}

CDD. 20.ed. 025.3

796

\author{
Suely ROSA* \\ J acqueline LETA*
}

*Centro de Ciências da Saúde, Universidade Federal do Rio de Janeiro.

\begin{abstract}
Resumo
A fim de contribuir com o debate sobre a heterogeneidade epistemológica da Educação Física (EF) e a falta de critérios adequados para avaliar a pesquisa e estudos com enfoques pedagógicos e socioculturais, o presente trabalho se propõe a caracterizar a pesquisa atual em EF que tem origem nos programas de pós-graduação (PGs) no Brasil. A pergunta central é qual a principal tendência epistemológica da pesquisa originada nas PGs em EF no Brasil? Partindo desta pergunta, iniciamos uma detalhada análise da produção acadêmica de 11 PGs inseridos na área de avaliação de Educação Física. A análise baseou-se nos relatórios anuais do triênio 2001/2003, disponiveis "on-line" pela CAPES e que apresentavam as produções bibliográficas de cada PG. No total foram analisados 5.628 títulos dos diversos tipos de produção bibliográfica. Os dados sugerem que a pesquisa em EF, gerada pelas PGs, tem visibilidade muito restrita, uma vez que livros e anais, com circulação limitada, constituem-se nos principais veículos para difundir o conhecimento em EF. Os dados também indicam a prevalência de estudos com base biológica e, apoiados principalmente na fisiologia, o que reflete a construção histórica da área de EF. Entretanto, observou-se também um forte influência de outras disciplinas, ou em outras palavras uma grande heterogeneidade epistemológica.
\end{abstract}

Unitermos: Educação Física; Pós-graduação; Pesquisa; Visibilidade; Multidisciplinar.

\section{Introdução}

Durante a Idade Média, o cristianismo pregava que para se alcançar a salvação da alma as atividades relacionadas ao corpo deveriam ser desprezadas (RAMOS, 1983, p.165). A prática de atividade física também não era recomendada para fins pedagógicos, especialmente na educação voltada às classes mais pobres, que estava confiada essencialmente à Igreja (CAMBI, 1999, p.296). Este cenário se modifica a partir do século XIV, quando um movimento de valorização de aspectos e ideais do ser humano se difunde por diferentes setores. Ao contrário da ideologia difundida na Idade Média, com o Humanismo as atividades físicas e os jogos são entendidos como um meio de educar e passam a ser valorizados assim como os aspectos psicológicos, morais e sociais da infância.

É a partir desta valorização e da concomitante organização do conhecimento em disciplinas, que a Educação Física (EF) começa a ser introduzida nas escolas. O processo de sistematização desta área tem início na Europa através dos sistemas ginásticos e mais tarde pelo desporto. O "Philantropinum", criado em 1774, por Johann Bernhard Basedow, foi a primeira escola a incluir a ginástica no currículo no mesmo plano das disciplinas teóricas, marcando, assim, o início da incorporação da EF pelo sistema de educação formal (MarinHo, 1980; RaMos, 1983). Porém, é na Inglaterra, por influência do contexto sócio-político da época, que a prática do desporto é apropriada pela EF, organizando-se de forma mais consistente para fins educativos (RAmos, 1983, p.230). Neste processo, os jogos começaram a ser ensinados em todas as "public schools", ganhando rápida difusão entre os jovens.

Aos poucos, os sistemas ginásticos e o desporto passaram a ser adotados pelos sistemas de educação formal de diversos outros países. Por traz disso, estava a percepção, especialmente de filósofos e 
pedagogos, do potencial da atividade física como veículo para a formação dos estudantes. Entretanto, no início, essa nova disciplina escolar era ministrada por instrutores ou por militares, ainda sem preparação específica. Segundo Ramos (1983), esse quadro começa a se modificar com a fundação de algumas escolas específicas na Europa, tais como Real Instituto Central de Ginástica em Estocolmo, Suécia, em 1813 (hoje Escola Superior de Ginástica e Desporto) e a Escola Normal Civil e Militar de Ginástica da França, em 1820. Posteriormente, outras escolas superiores voltadas para a formação do profissional em EF são fundadas não somente na Europa, mas também nos EUA (Mесhiкoff \& Estes, 1998).

No Brasil, a fundação da Escola Superior de Educação Física do Estado de São Paulo, em 1934, e da Escola Nacional de Educação Física e Desportos (ligada à Universidade do Brasil, atual UFRJ), em 1939, são marcos da incorporação da EF no ensino superior brasileiro. No entanto, segundo MARINHO (1980), movimentos em prol da EF têm início ainda no Brasil império, a partir de conferências, elaboração de livros e de outras iniciativas. Neste período, surgem os primeiros clubes que ofereciam infra-estrutura, estimulando, assim, a prática de formas variadas de atividades físicas. Já no Brasil República, a prática de jogos nos jardins de infância das escolas públicas ganha apoio legal, após regulamentação específica, tal como a aquela referente à Reforma Fernando
Azevedo, em 1928, que tornou a EF obrigatória nas instituiçōes de educação em nível de ensino primário, normal e profissional (MARINHO, 1980, p.172). Essa lei gerou demanda específica para formação de profissionais na área, motivação necessária para a criação das primeiras Escolas Superiores de EF no país; fato já ocorrido na Europa e EUA há mais de um século.

\section{A pós-graduação em Educação Física no Brasil}

Se por um lado os cursos de graduação em EF ganharam espaço no Brasil ainda na primeira metade do século XX, a criação dos primeiros cursos de pós-graduação $(\mathrm{PG})$ ainda teve que aguardar algumas décadas. A primeira instituição a oferecer um curso de mestrado e doutorado em EF no Brasil foi a Universidade de São Paulo, em 1977 e 1988, respectivamente (FIGURA 1). Segundo BetTi (1991) citado por VerENGUER (1997) alguns fatores foram fundamentais para a consolidação das PGs em EF no Brasil, dentre eles: o retorno de pós-graduandos brasileiros que se encontravam no exterior, a sistematização de eventos científicos, a fundação de periódicos da área e um ambiente favorável ao desenvolvimento da pesquisa em EF.

Mas foi a partir dos anos 80 , que as pós-graduações em EF cresceram e se espalharam por todo o país, vinculadas tanto a instituiçôes públicas como privadas.

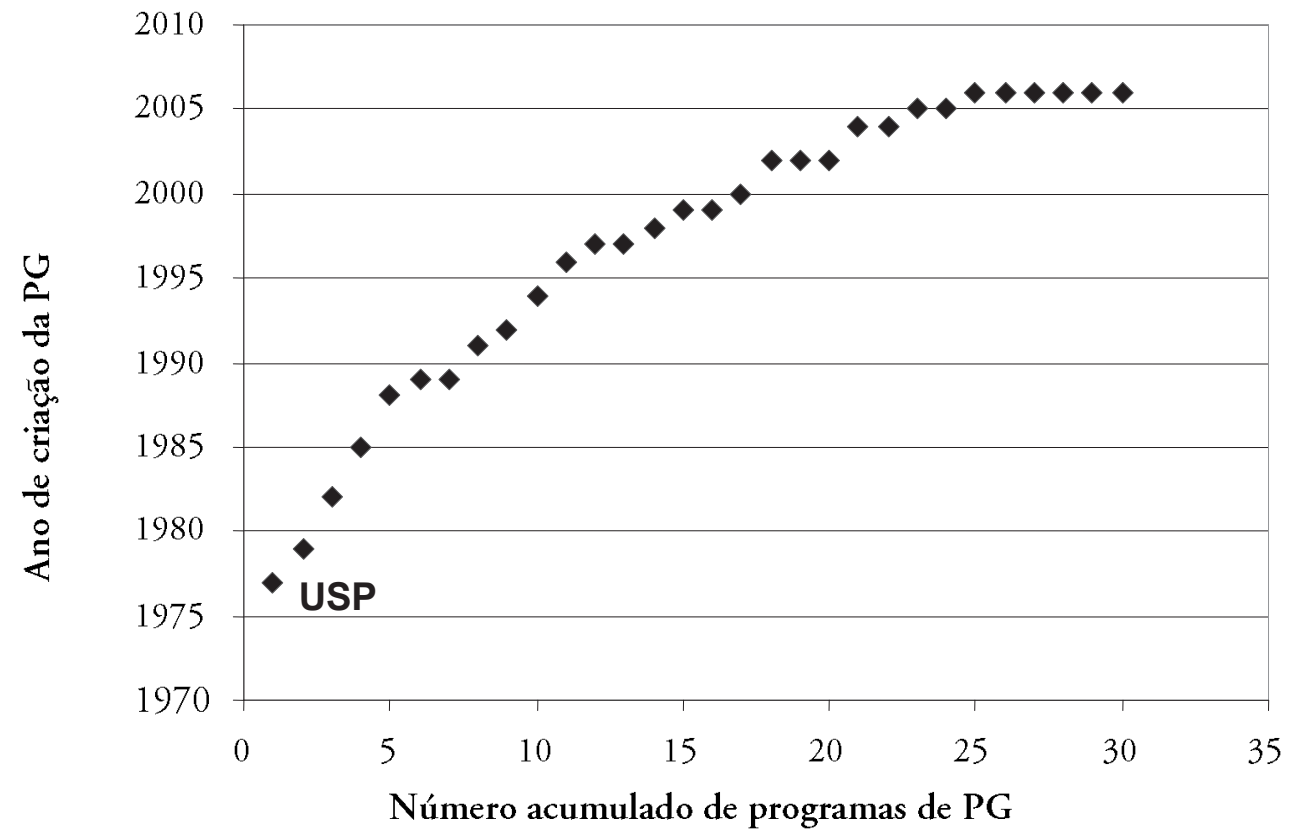

FIGURA 1 - Evolução da PG na área de Educação Física no Brasil. 
KOKUBUN (2003) confirma o crescimento do número de programas de PGs em EF no Brasil, mas ressalta que esse crescimento oculta enormes desafios. Dentre eles, o autor destaca a manutenção da qualidade dos programas, a reflexão sobre sua base epistemológica, o aumento da quantidade e da qualidade da produção intelectual, a redução da heterogeneidade da produção docente e a formação de docentes de ensino superior voltada para a pesquisa e não apenas para o ensino.

A partir de dados coletados pela Coordenadoria de Aperfeiçoamento de Pessoal de Nível Superior (CAPES), para o período de 1996 a 2001, KoKUBUN (2003) destaca que as PGs em EF no Brasil enfatizam a formação de recursos humanos para as atividades de ensino. Tal cenário tem como base a análise realizada pelo autor sobre a produção intelectual gerada nestes programas, que apontou para uma produção essencialmente doméstica, com pouca visibilidade internacional. $\mathrm{O}$ autor também analisa o desempenho individual dos docentes vinculados aos programas de $\mathrm{PG}$ e percebe que somente $1 / 3$ deles atinge o mínimo de publicações exigido pela CAPES para uma boa avaliação das atividades de pesquisa.

Em 2008, as PGs em EF no Brasil somavam 29 com mestrado e 13 com doutorado. Todos estes programas se encontram vinculados à grande área do conhecimento das Ciências da Saúde e eram avaliados segundo critérios objetivos que valorizam alguns aspectos, são eles: a proposta do programa, a qualificação do corpo docente, as atividades de pesquisa, as atividades de formação, as teses e dissertações e a produção intelectual de docentes e discentes do programa (CAPES, 2008).

\section{Procedimentos metodológicos}

Este trabalho insere-se em um projeto que busca entender a pesquisa em EF no país a partir de diferentes abordagens. Na parte 1 deste estudo, analisamos quatro periódicos nacionais a fim de caracterizar a pesquisa contemporânea brasileira em EF. Nesta parte, o foco está sobre os programas de PGs da área de EF, os quais têm sido cada vez mais exigidos a produzir e publicar o conhecimento gerado por eles em veículos classificados em um "ranking" de visibilidade, que vai daqueles veículos mais locais aqueles mais internacionais. Como, então, se configura esta produção em relação às disciplinas e abordagens?
O uso de critérios objetivos, dentre os quais as publicações internacionais, para avaliar as PGs e a pesquisa em EF no Brasil tem gerado intenso debate na área (Betti, Carvalho, Daolio \& Pires, 2004; KoKUBUN, 2003; LovisOlo, 2007; TANI, 2007). Na base desta discussão estão, pelo menos, dois aspectos: a diversidade temática, ou em outras palavras, a heterogeneidade epistemológica da EF e falta de critérios adequados para avaliar o desempenho de pesquisadores que desenvolvem pesquisas e estudos em temáticas de EF com enfoques pedagógicos e socioculturais. Para BETTI (2003), BRACHT (1999) e LOVISOLO (1998) uma área multidisciplinar como a $\mathrm{EF}$ - que tem base em diferentes tradiçōes disciplinares e, portanto, diferentes pressupostos - dificilmente alcançará uma unidade epistemológica (BETTl et al., 2004, p.189).

Assim, com o propósito de contribuir com este debate, o presente trabalho se propóe a caracterizar a pesquisa atual em EF que tem origem nos programas de pós-graduação no Brasil. Na parte 1 deste projeto que estamos conduzindo, nos debruçamos sobre algumas revistas nacionais voltadas para a pesquisa em EF. Dentre outros aspectos, percebemos que o caráter multidisciplinar está presente nas publicaçōes analisadas, mas é na disciplina "fisiologia" que repousa o maior enfoque da pesquisa em EF no Brasil. Neste trabalho, que entendemos ser uma continuidade do anterior, a pergunta central é qual a principal tendência epistemológica da pesquisa originada nas PGs em EF no Brasil? Será que o perfil desta produção se assemelha aquele nos periódicos nacionais? Para responder esta pergunta, mergulhamos no universo das PGs e apresentamos também algumas outras características que possibilitam visualizar a diversidade entre elas.
Assim, partindo desta pergunta, foram coletados os relatórios anuais referentes às produções bibliográficas de 11 programas de pós-graduação, todos inseridos na área de avaliação e área básica de Educação Física. Estes representam somente os programas específicos de Educação Física, Motricidade ou Movimento Humano. Os relatórios analisados referem-se ao triênio 2001/2003, todos disponíveis "on-line" pela CAPES (2007). Estes 11 programas constavam na lista de programas ativos e avaliados pela CAPES em 2004, mas três deles não apresentaram relatórios em um ou dois anos de avaliação, uma vez que haviam sido recém criados (QUADRO 1). A escolha desta 
janela temporal, o triênio 2001/03, deve-se ao fato de que quando este projeto iniciou-se, ainda não estavam finalizadas e disponíveis as avaliações do triênio 2004/2006. Além disso, esse o referido triênio é também o período da análise que realizamos sobre o perfil das revistas (Parte 1).

QUADRO 1- Programas de Pós-graduação em Educação Física no Triênio 2001/2003.

\begin{tabular}{|lcccc|}
\hline \multicolumn{1}{|c}{ PROGRAMAS DE PG EM EF } & \multicolumn{3}{c}{ Relatório CAPES } & $\begin{array}{c}\text { Produção } \\
\text { intelectual }\end{array}$ \\
\hline Ciências da Motricidade / UNESP - RC & Ano & Ano & Ano & 2001 \\
Educação Física / USP & 2001 & 2002 & 2003 & 1110 \\
Educação Física / UNICAMP & 2001 & 2002 & 2003 & 839 \\
Educação Física / UFSC & 2001 & 2002 & 2003 & 793 \\
Ciências do Movimento Humano / UDESC & 2001 & 2002 & 2003 & 709 \\
Educação Física / UGF & 2001 & 2002 & 2003 & 584 \\
Ciência da Motricidade Humana / UCB - RJ & 2001 & 2002 & 2003 & 338 \\
Ciências do Movimento Humano / UFRGS & 2001 & 2002 & 2003 & 299 \\
Educação Física / UCB & & 2002 & 2003 & 218 \\
Educação Física / UNIMEP & & & 2003 & 106 \\
Educação Física / UFPR & & & 2003 & 101 \\
Total de produção intelectual & 1451 & 1889 & 2288 & 5.628 \\
\hline
\end{tabular}

Após a coleta, cada um dos 28 relatórios teve toda a informação bibliográfica extraída manualmente para uma planilha em Excel 2.0. Ao final, foram coletados 5.628 títulos dos diversos tipos de produção bibliográfica publicados pelos 11 programas. Cada título contém várias informaçōes, tais como: autoria, referência completa, classificação segundo os critérios Qualis. A estas informações foram agregadas outras, em particular, a temática central da publicação, a disciplina, a grande área e a abordagem. Detalhes desta classificação estão descritos em Rosa e LeTA (2010).

\section{Resultados}

Os resultados apresentados a seguir estão organizados em dois blocos principais: 1) a visibilidade e 2) a heterogeneidade epistemológica da pesquisa gerada pelas PGs em EF.

\section{A visibilidade da pesquisa em Educação Física: qual o público alvo das PGs?}

Segundo os critérios de avaliação da CAPES para os programas de $\mathrm{PG}$ da grande área da saúde, no item 'produção intelectual', os trabalhos impressos originados pelas $\mathrm{PGs}$ em EF são classificados em uma escala decrescente, que vai da nota $\mathrm{A}, \mathrm{B}$ ou $\mathrm{C}$, em Internacional, Nacional ou Local. A pontuação dos programas se baseia nessa escala hierárquica, onde os trabalhos publicados em periódicos classificados como Internacional A são os de maior peso (CAPES, 2008).
A análise dos veículos utilizados pelos programas evidencia, no entanto, que a produção intelectual publicada em periódicos não é a de maior ocorrência, mas sim as publicaçōes em anais de congresso (FIGURA 2). No triênio, das 5.628 publicaçôes analisadas, encontramos $3.594 \mathrm{em}$ anais, 1.377 em periódicos $\mathrm{e}$ 657 em livros e/ou capítulos de livros. Apesar de haver alguma tendência de mudança, este perfil pouco se altera quando comparamos os dados de 2001 com aqueles de 2003 (dados não apresentados).

Importante perceber que a tendência de publicar em anais não tem relação com volume de publicações das PGs e é justificada pela "tradição bem-sucedida na realização de eventos científicos de grande porte, de boa qualidade, tanto em conteúdo como em forma, nos quais se reúnem e interagem pesquisadores experientes e iniciantes. 
Nós gostamos de nos encontrar e debater de viva voz" (BETTI et al., 2004, p.187).

Já a análise do desempenho destes programas em relação à visibilidade da produção intelectual publicada em periódicos $(\mathrm{n}=1.377)$ - Classificação Qualis - mostra uma predominância em periódicos nacionais: no total foram 877 publicaçôes nestes periódicos, o que representa $64 \%$ do montante de trabalhos neste formato. Esse dado corrobora a observação de KoKUBUn (2003), quanto ao baixo impacto da produção intelectual das pós-graduações em EF. A análise por programa mostra, no entanto, que esta é uma tendência que não se repete em todas as PGs (FIGURA 3).

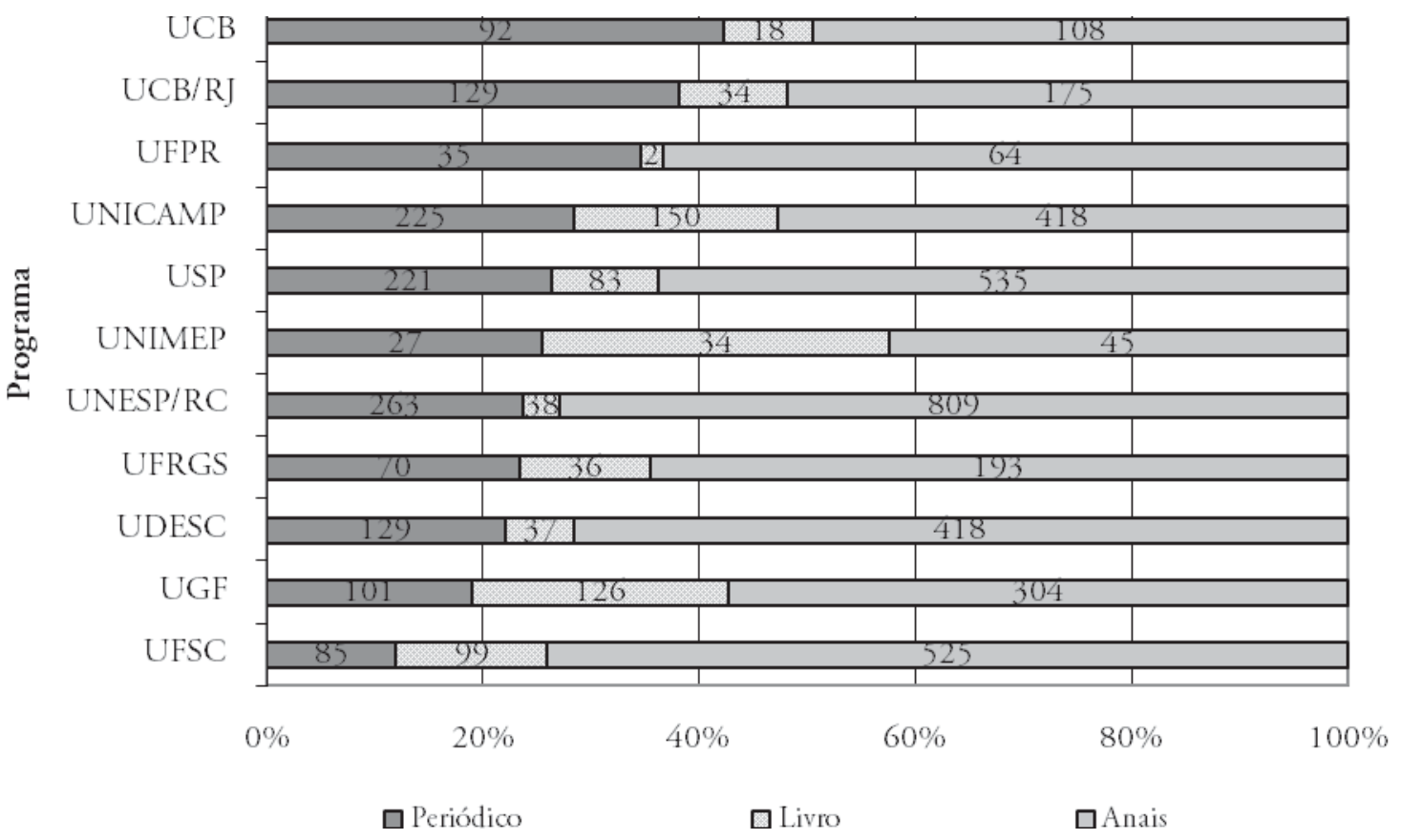

FIGURA 2 - Produção intelectual das PGs em Educação Física segundo o meio de divulgação, 2001-2003.

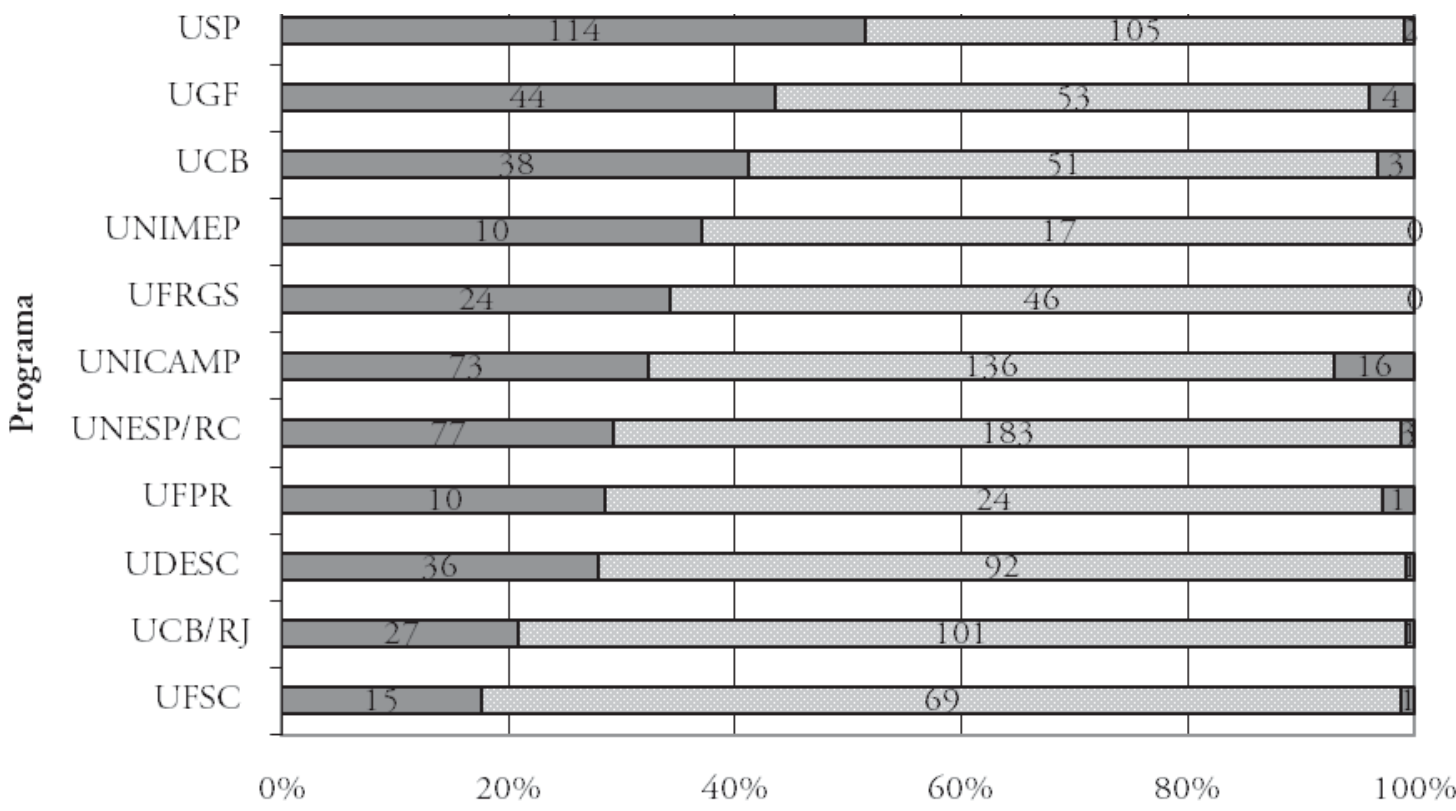

Qualis Int $\square$ Qualis Nac $\square$ Qualis Local

FIGURA 3 - Publicações em periódicos das PGs em Educação Física segundo a classificação Qualis, 2001-2003. 
A análise comparativa entre 2001 e 2003 indica um tímido crescimento das publicações em periódicos internacionais (dados não apresentados). De fato, ao analisar mais detalhadamente os periódicos, é possível evidenciar a forte presença de artigos escritos em Português e/ou em periódicos nacionais, a qual se mantém ao longo dos três anos analisados. Esta predominância fica bem evidenciada na análise apresentada no QUADRO 2. Do total de artigos publicados (1377) pelos programas, cerca de $80 \%$ são escritos em português. Dentre o total de periódicos onde são publicados os artigos dos programas, observa-se também o peso dos periódicos nacionais, que representam cerca de $60 \%$ do total. Já entre os periódicos centrais, aqueles onde $1 / 3$ dos artigos de nossa amostra foram publicados e são considerados o núcleo central da área (BRADFORD, 1934), apenas o FIEP Bulletin (que, apesar de aceitar trabalhos em português, pertence a uma associação internacional) não é nacional. Importante aqui destacar que dentre os periódicos centrais estão três dos quatro periódicos considerados na parte 1 deste estudo (RosA \& LETA, submetido), um indicativo da forte influência deles para a produção da academia.

QUADRO 2 - Distribuição de artigos e de periódicos - total e em Português - por ano.

\begin{tabular}{|c|c|c|c|c|c|c|c|}
\hline \multicolumn{3}{|c|}{ Artigos } & \multicolumn{2}{|c|}{ Periódicos } & \multicolumn{3}{|c|}{ Periódicos centraias } \\
\hline Ano & Total & Em português & Total & Em português & Total & Títulos & Artigos \\
\hline \multirow[t]{4}{*}{2001} & 279 & $222(79,6 \%)$ & 102 & $64(62,7 \%)$ & 5 & Motriz & 42 \\
\hline & & & & & & Rev. Paulista de Educação Física & 17 \\
\hline & & & & & & Rev.Brasileira de Ciência e Movimento & 13 \\
\hline & & & & & & Rev. Brasileira de Atividade Física e Saúde & 12 \\
\hline \multirow[t]{4}{*}{2002} & 461 & $388(83,2 \%)$ & 101 & $67(66,3 \%)$ & 3 & Rev. Brasileira de Ciências do Esporte & 10 \\
\hline & & & & & & Rev. Brasileira de Ciência e Movimento & 91 \\
\hline & & & & & & Rev. Brasileira de Medicina do Esporte & 42 \\
\hline & & & & & & Fitness and Performance Journal & 23 \\
\hline \multirow[t]{4}{*}{2003} & 637 & $501(78,6 \%)$ & 150 & $91(60,7 \%)$ & 4 & Motriz & 82 \\
\hline & & & & & & Rev. Brasileira de Ciência e Movimento & 63 \\
\hline & & & & & & Rev.Brasileira de Medicina do Esporte & 50 \\
\hline & & & & & & FIEP Bulletin & 27 \\
\hline
\end{tabular}

\section{A heterogeneidade epistemológica da pesquisa em EF: dilemas de uma área?}

Tal como sugerido por TANI (2000) citado por KoKUBUn (2003), a EF entendida como campo de conhecimento carece de uma unidade epistemológica. A análise das disciplinas que embasam a produção intelectual em Educação Física permite identificar a diversidade temática que compõe a pesquisa nesta área e, portanto, inferir sobre esta questão dentro dos programas de PGs. Assim, para as 5.628 publicações das PGs em EF, foram encontradas 136 temáticas, dispersas em 35 disciplinas. Dentre as temáticas mais frequentes encontram-se: fisiologia do exercício ( $\mathrm{n}$ = 527), testes e instrumentos de análise $(\mathrm{n}=488)$, biomecânica $(\mathrm{n}=310)$, aspectos sociais aplicados à EF $(n=299)$ e psicologia do esporte $(n=206)$.

$\mathrm{O}$ agrupamento destas temáticas permite visualizar tal diversidade. A FIGURA 4 mostra a distribuição segundo a "disciplina-mãe" de 5.301 publicaçôes, que representam $94 \%$ do volume analisado. Assim, é possível observar que apesar de as publicaçōes com temática na disciplina fisiologia predominarem, temáticas de outras disciplinas são também importantes para a produção das PGs em $\mathrm{EF}$, mesmo que ocorram em menor número. 


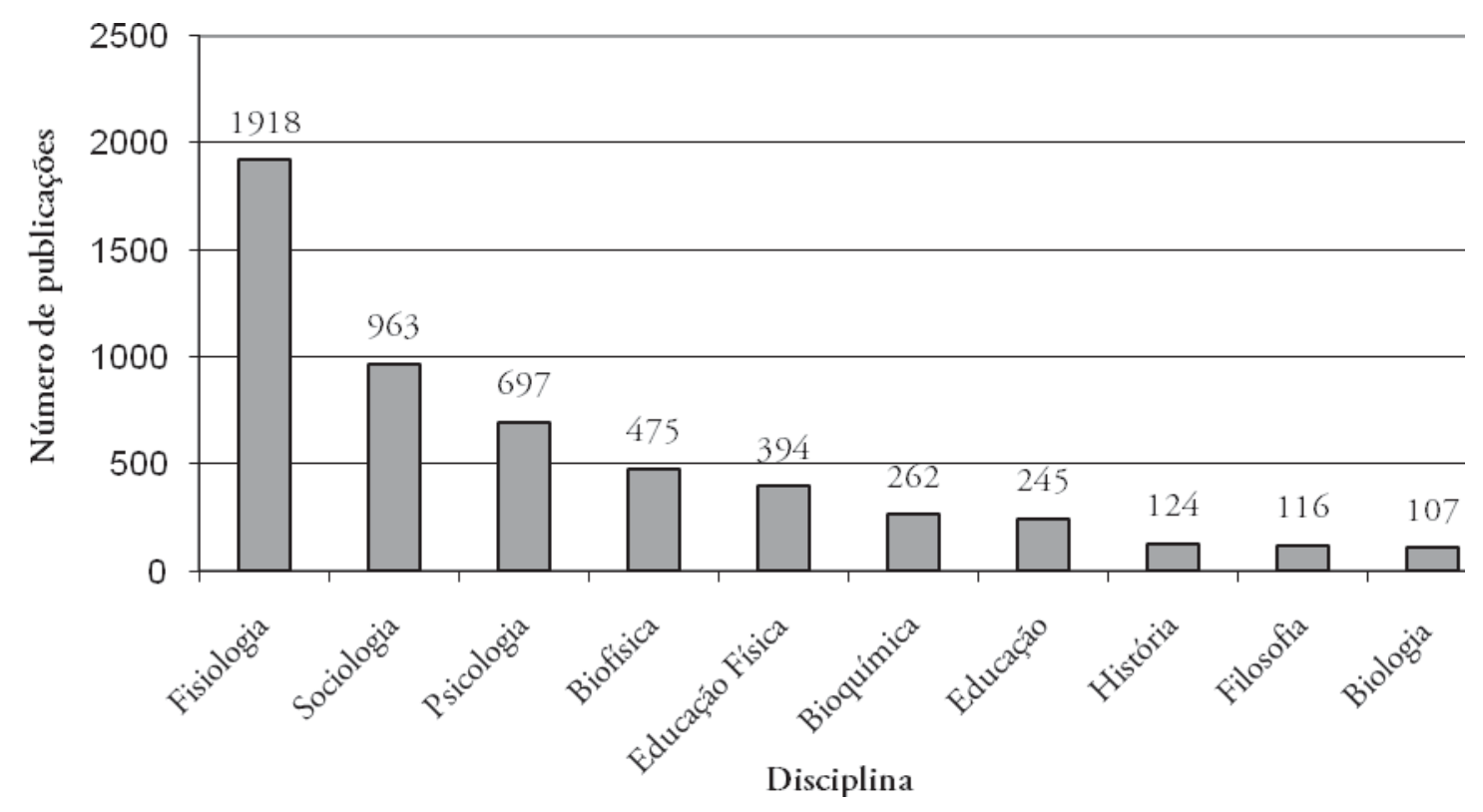

FIGURA 4 - Publicações das PGs em Educação Física segundo as disciplinas mais frequentes, 2001-2003.

A partir da classificação por disciplinas, as publicaçôes das PGs em Educação Física foram agrupadas segundo o tipo de abordagem: biológica ou não biológica. Temáticas com conteúdo no qual o uso da atividade física atendia a questões ligadas aos aspectos anatômicos, bioquímicos, biofísicos, biológicos, fisiológicos, médicos, de reabilitação e da saúde do ser humano, foram classificadas como de abordagem biológica. As demais foram classificadas como abordagem não biológica. Assim, dos 5.628 títulos analisados, 5.600 puderam ser classificados, e deste total, $2.981(53,2 \%)$ estão voltados para temas e/ou foco com abordagem biológica, enquanto $2.619(46,8 \%)$ têm abordagem não biológica, uma relação que se mantém estável ao longo dos três anos analisados.

Em um estudo anterior, FARIA JUNIOR (1987) citado por OliveIRa (1994) identificou, no período de 1975 a 1984 , que $64,5 \%$ das publicações em EF apresentavam preocupações de ordem biológica / técnica. Já RosA e LETA (2010) identificaram que $73 \%$ dos artigos publicados em quatro periódicos nacionais apresentavam abordagem biológica e 27\% abordagem não biológica. Nestes dois trabalhos, é possível observar uma diferença marcante na presença destas duas abordagens, biológica e não biológica. Quando olhamos para toda nossa amostra
( $\mathrm{n}=5.628)$ não encontramos esta mesma tendência. No entanto, quando examinamos individualmente para o total da produção acadêmica de cada uma das PGs analisadas, observamos uma variação maior entre estas abordagens (FIGURA 5).

A análise institucional mostra que a pesquisa com abordagem biológica é muito mais frequente em cinco dos 11 programas analisados. Nestes programas, mais de $60 \%$ das publicações apresentam esta abordagem. Há um segundo grupo, com 5 PGs, que se assemelha mais ao padrão que encontramos para o total da amostra, ou seja, a fração de publicações com abordagem biológica e não biológica não difere significativamente. E finalmente, há um único caso, o programa da UGF, que mostra uma tendência muito forte de publicações com abordagem não biológica. Estes dados indicam o caráter multifacetado da área.

Ao longo dos três anos, verificamos um discreto (aproximadamente 7\%) aumento quantitativo de publicações com abordagem biológica em periódicos e um pequeno decréscimo em anais (dados não apresentados). Já as publicações com abordagem não biológica aumentam nos artigos em periódicos no último ano do triênio somente, mas em si tratando de anais, observou-se um crescimento ao longo de todo o triênio. 


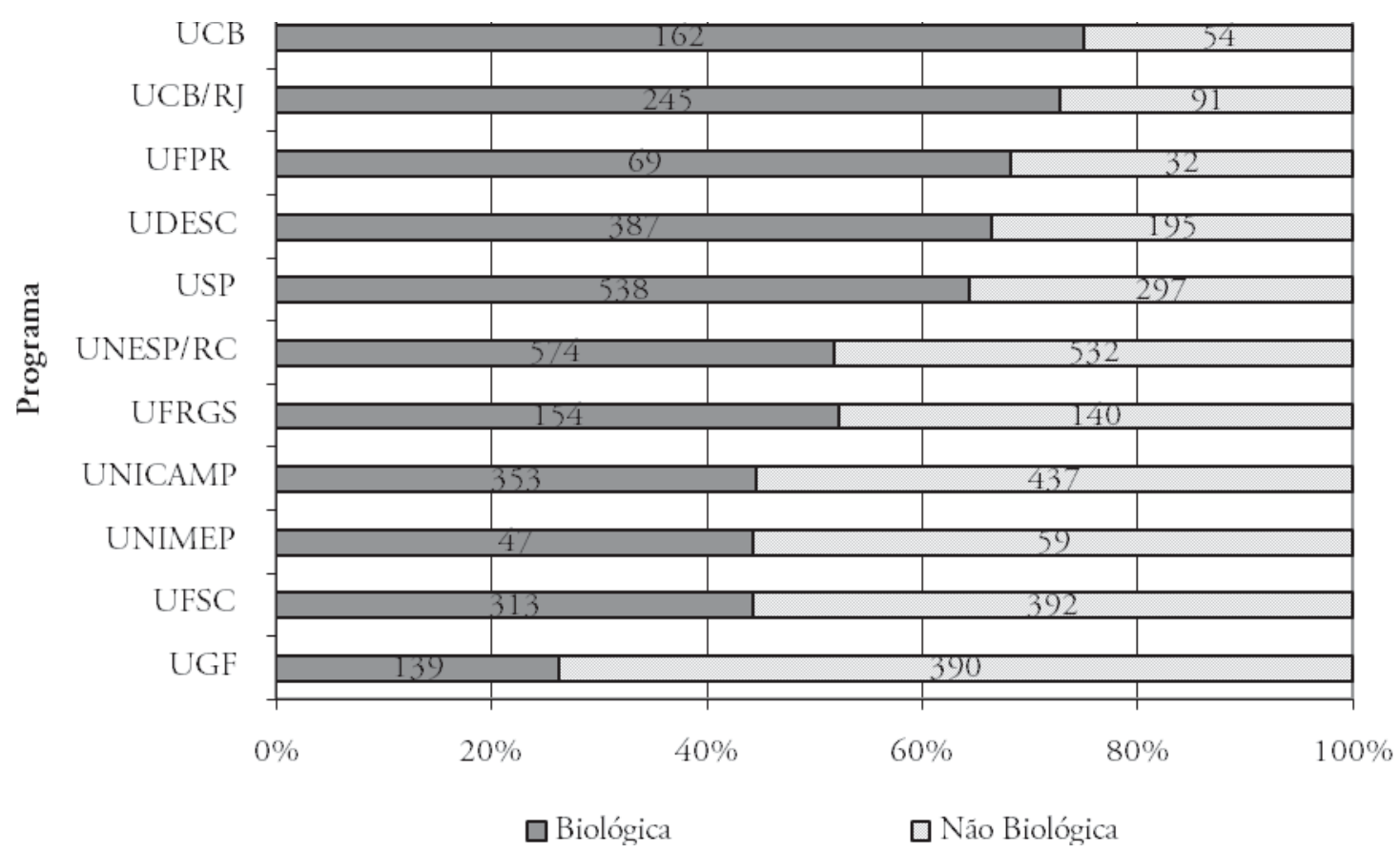

FIGURA 5 - Publicações das PGs em Educação Física segundo a abordagem, 2001-2003.

\section{Diversidade epistemológica versus a visibilidade da pesquisa}

Considerando a relação entre o tipo de abordagem - biológica e não biológica - e o tipo de veículo, é possível verificar que nos periódicos predominam as produções com abordagem biológica (FIGURA 6A). Já nos anais, há praticamente uma equivalência na frequência de ambas as abordagens, enquanto nos livros predominam aquelas com abordagem não biológica. BetTI et al. (2004) explicam esse comportamento informando que:

É preciso compreender que, nas Ciências Humanas, o livro/capítulo de livro, muitas vezes, divulga o próprio relatório da pesquisa realizada e é o veículo mais adequado para os trabalhos nessa área que, por sua natureza e características, são, em geral, mais longos e cujo conteúdo ficaria prejudicado se restrito às poucas páginas permitidas nas revistas científicas. Tal não parece ocorrer nas Biológicas ou Exatas, áreas em que o livro costuma ter caráter didático e/ou de revisão; de fato, a proporção de livros/capítulos é bem menor nessas duas grandes áreas. Particularmente na subárea pedagógica e sociocultural da Educação Física, os livros e capítulos têm tido papel importante porque nela ainda se estão abrindo novas frentes de investigação, nas quais os livros costumam funcionar como referência inicial. Muitos livros resultaram - e muitos ainda resultarão - da publicação de dissertaçóes e teses "pioneiras" na área.

Esse dado sugere uma relação entre visibilidade e abordagem. Os livros que, em geral, tem uma circulação mais limitada e, portanto, visibilidade mais local são os veículos que mais divulgam o conhecimento em EF com abordagem não biológica. Por outro lado, os periódicos, que podem ter uma circulação mais ampla, mostram um perfil oposto. Uma análise mais detalhada dos periódicos (FIGURA 6B) mostra que esta mesma relação ocorre também entre eles. É fácil observar que quanto maior o Qualis, ou seja, quanto maior a visibilidade dos periódicos, maior a proporção de artigos com abordagem biológica. E se o artigo está escrito em língua inglesa (FIGURA 6C), maior ainda é a frequência de publicações com abordagem biológica. Importante destacar que neste grupo de publicações há uma forte presença de periódicos com enfoque nas ciências biológicas. Os periódicos que concentram $1 / 3$ dos artigos em inglês mostram tal tendência, são eles: FIEP Bulletin ( ${ }^{\circ}$ de artigos $=22)$, Medicine and Science in Sports and Exercise $(n=21)$, Brazilian Journal of Medical and Biological Research $(n=10)$, Electromyography and Clinical Neurophysiology $(\mathrm{n}=9)$ Journal of Hypertension $(\mathrm{n}=8)$, Neuroscience Letters $(\mathrm{n}=7)$ e Cell Biochemistry and Function $(n=7)$.

$\mathrm{O}$ conjunto de resultados apresentados sugere, assim, que a produção de artigos das PGs em 
EF com abordagem biológica está voltada para um público especializado, de pesquisadores com interesses comuns a esta abordagem, os pares. Já aquelas produções com abordagem não biológica, a se considerar todos os formatos de publicações, estão principalmente voltadas para um público local, o qual não necessariamente é formado por especialistas.

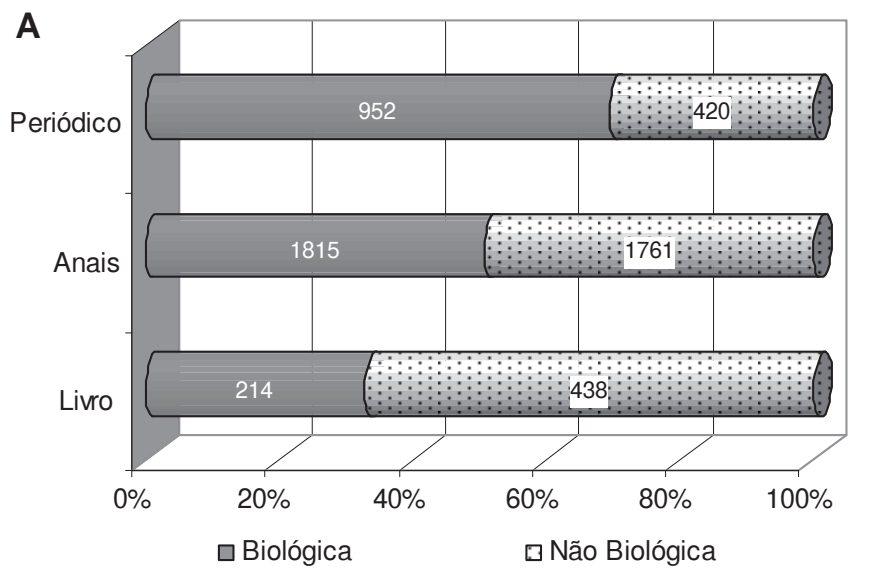

I = Periódico internacional;

$\mathrm{N}=$ Periódico nacional; $L=$ Periódico local.

As letras $A, B$ e $C$ que acompanham o I ou o N correspondem ao nível de impacto desses periódicos, que não ocorre nos periódicos $L$.
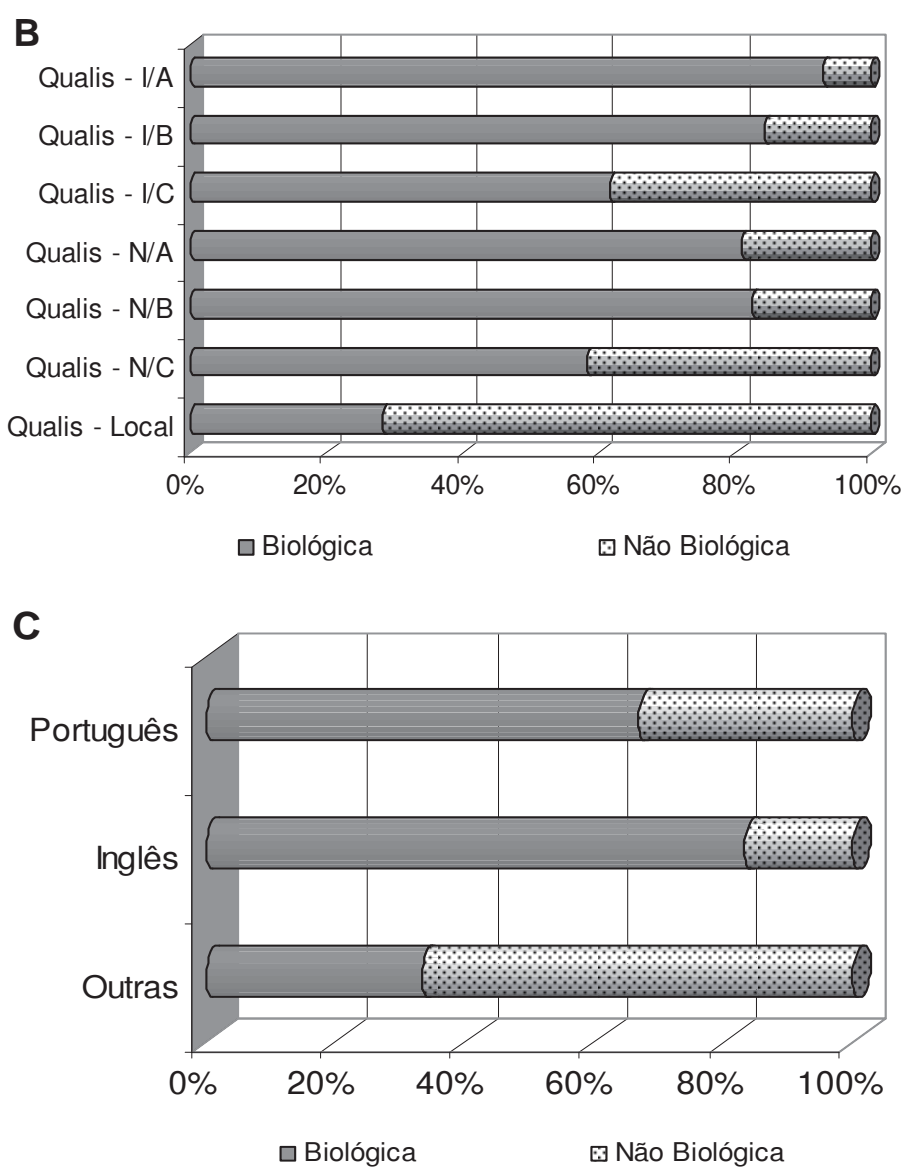

FIGURA 6 - Abordagem Biológica e Não Biológica nas Publicações das PGs em Educação Física: relação com o formato da publicação (A), com visibilidade do periódico (B), e língua do artigo (C) 2001-2003.

Na TABELA 1 é possível identificar as abordagens adotadas pelos diferentes programas e inferir sobre a visibilidade das suas produções. Independente da abordagem, o veículo mais utilizado pelos programas são os anais de Congressos, indicando a importância destes eventos na divulgação dos novos conhecimentos produzidos na área. Em relação aos artigos em periódicos, aqueles com abordagem biológica 
predominam quantitativamente na maior parte dos programas; um indicativo do maior interesse dos pesquisadores por pesquisas com esta abordagem. A comparação com a FIGURA 5 sugere, então, que a tendência biológica ou não biológica apontada para os programas pode ser diferente se considerarmos o total da produção ou somente os artigos em periódicos, por exemplo.

TABELA 1 - Publicações das PGs em Educação Física segundo a abordagem e formato, 2001-2003.

\# A diferença entre 0 total da produção intelectual das PGs no triênio e o total desta tabela refere-se às publicações que não conseguimos classificar em disciplinas.

\begin{tabular}{lccccccc}
\hline & \multicolumn{9}{c}{ Biológica } & \multicolumn{5}{c}{ Não Biológica } & \multirow{2}{*}{ Total } \\
\cline { 2 - 6 } & Anais & Artigo em periódico & Livro & Anais & Artigo em periódico & Livro & \\
\hline UNESP/RC & 363 & 199 & 12 & 443 & 63 & 26 & 1106 \\
USP & 317 & 177 & 44 & 215 & 44 & 38 & 835 \\
UNICAMP & 194 & 127 & 32 & 222 & 98 & 117 & 790 \\
UFSC & 226 & 50 & 37 & 296 & 35 & 61 & 705 \\
UDESC & 265 & 100 & 22 & 152 & 28 & 15 & 582 \\
UGF & 62 & 54 & 23 & 242 & 46 & 102 & 529 \\
UCB/RJ & 139 & 95 & 11 & 36 & 33 & 22 & 336 \\
UFRGS & 110 & 35 & 9 & 78 & 35 & 27 & 294 \\
UCB & 86 & 66 & 10 & 21 & 25 & 8 & 216 \\
UNIMEP & 14 & 20 & 13 & 31 & 7 & 21 & 106 \\
UFPR & 39 & 29 & 1 & 25 & 6 & 1 & 101 \\
& 1815 & 925 & 214 & 1761 & 420 & 438 & $5600 \#$ \\
\hline
\end{tabular}

\section{Considerações finais}

Neste trabalho, focamos nossa atenção para a pesquisa originada em 11 PGs em EF, credenciadas e ativas no período de 2001-2003. Todas as análises tiveram como base os relatórios enviados pelas 11 PGs à CAPES, como parte da avaliação institucional organizada pela agência, cujo enfoque central se dava a partir da qualificação Qualis da produção. A partir de 2009 , no entanto, um novo modelo de avaliação institucional foi implantado, substituindo aquele já consolidado, o Qualis. Assim, entendemos que há um "gap" temporal com os dados aqui apresentados e discutidos, que tem a base em um modelo de avaliação que já não existe mais. Acreditamos, no entanto, que este "gap" não invalida os dados que apresentamos. Estes servem como importantes ferramentas para auxiliar na reflexão e discussão em torno da heterogeneidade da pesquisa em EF no país. Os dados são um retrato daquilo que as PGs produziram em um período recente da nossa história, onde foram submetidos a um modelo de avaliação que privilegiava a produção internacional. Neste item específico, o modelo atual de avaliação parece não divergir do anterior, o que corrobora ainda mais a validade de nossos dados.
Assim, apesar de tal "gap", as informaçóes geradas neste trabalho levantam evidências acerca da visibilidade e da heterogeneidade da produção em EF gerada pelas PGs, o "carro-chefe" da pesquisa brasileira.

Sobre a visibilidade, os dados apontam para uma pesquisa voltada para um público essencialmente local (FIGURA 2 e 3). Este mesmo público tem acesso a um conhecimento em EF que traz prioritariamente uma abordagem não biológica. Já para o público internacional, a pesquisa brasileira em EF apresenta principalmente abordagem biológica.

Sobre a heterogeneidade temática da pesquisa brasileira em EF, os resultados indicam a prevalência, ainda hoje, de estudos com base biológica e, apoiados principalmente na fisiologia, o que reflete a construção histórica da área de EF. Entretanto, percebe-se, também, um crescimento da pesquisa com fundamentação nas ciências humanas mostrando, assim, uma possível mudança em relação à construção inicial desse campo de conhecimento. Dessa forma, esse estudo aponta para um perfil multidisciplinar da EF e demonstra os múltiplos enfoques da pesquisa gerada pelos PGs nesta área, o que vai ao encontro dos dados e discussão apresentados na parte 1 deste trabalho. 
A partir do conhecimento das disciplinas que ancoram as pesquisas geradas nos programas em EF é possível inferir sobre as concepçôes que norteiam a produção intelectual da EF. Assim, considerando aqueles trabalhos que têm relação direta com disciplinas como a fisiologia, biofísica e bioquímica, é possível acreditar que eles carregam uma concepção de EF voltada para o rendimento, a melhoria da aptidão física e da saúde. Dessa forma, ao se considerar a EF sob a perspectiva da biologia, o movimento humano será visto "não como construção social e histórica e, sim, como elemento natural e universal, portanto, não histórico, neutro política e ideologicamente, características que marcam, também, a concepção de ciência onde vão sustentar suas propostas" (BRACHT, 2007).

Já aqueles trabalhos relacionados com a sociologia, bem como a filosofia e a história podem apresentar uma concepção de EF ligada principalmente à cultura corporal ou cultura corporal de movimento que tem por característica correlacionar a prática da atividade física às suas dimensōes histórica e social (SOARES, TAFFAREL \& ESCOBAR, 2005). Os trabalhos voltados para temáticas da educação - como a didática, o currículo, as estratégias e métodos de ensino - parecem considerar o movimento humano sob o olhar pedagógico, isto é, dentro de uma concepção pedagógica de EF.

Os dados sugerem que a pesquisa em EF, gerada pelas PGs, ainda que apontem grande ênfase nos aspectos biológicos do corpo e do exercício, tem um forte caráter multidisciplinar, ou em outras palavras uma grande heterogeneidade epistemológica. Mas será que esta pesquisa multidisciplinar está voltada para atender questôes relacionadas às diferentes realidades sociais, como a prática pedagógica (ligada à educação formal)? Será que tem relação com práticas informais de atividade física, como as atividades executadas de forma espontânea e sem regularidade nos momentos de lazer, por exemplo? Ou estarão mais preocupadas em responder as questōes relacionadas com as práticas regulares de atividades físicas/treinamento em academias e clubes? Assim, perguntas como estas - que os dados do presente trabalho não permitem responder - são essenciais para entender a dinâmica não só da pesquisa mas da EF como um todo.

Há, sem dúvida, diferenças significativas na forma de entender a EF como campo de conhecimento. $\mathrm{Na}$ perspectiva pedagógica, ela tem uma ligação estreita com as ciências da educação, mas, do ponto de vista de atividades de treinamento para a melhoria do rendimento ou de manutenção da aptidão física e da saúde, a EF tem relação com as ciências que fundamentam os desempenhos esportivos e o fitness. Assim, é possível inferir que essa heterogeneidade epistemológica é própria deste campo de conhecimento.

Para este recorte temporal, nossos dados apontam que vivemos um momento em que, apesar da característica multifacetada, a pesquisa das PGs em EF no país enfatiza a concepção biológica. As motivaçōes que estão por traz deste perfil podem ser as mais variadas, tais como: financiamentos específicos que privilegiam os projetos e pesquisas com este foco, avaliaçóes que valorizam a produção acadêmica de maior visibilidade, a busca por maior "status" e/ou reconhecimento do pesquisador. Estes fatores e outros não apresentados aqui estão em sintonia com a reflexão apresentada por BOURDIEU (2005) acerca do acúmulo de capital simbólico no meio acadêmico e científico. Pesquisadores envolvidos e dedicados à temáticas da EF com ênfase nas ciências biológicas estariam, neste momento, com capital científico maior. Assim, em um movimento histórico-social de circularidade, ora uma concepção poderá receber mais ênfase, ora a outra.

\section{Abstract}

Trends on the Brazilian research in Physical Education. Part 2: a view through the epistemological diversity in graduate programs

In order to contribute to the national debate on the epistemological heterogeneity in the field of Physical Education (PE) and to the lack of adequate criteria to evaluate research in PE that emphasizes social and pedagogical aspects, the present study aims to characterize current Brazilian research on PE published by Graduate Programs (GP). The research question is: what is the main epistemological trend of research originated in Brazilian GPs? The data consist of a detailed analysis of the academic production of 11 GPs in PE, based on the GP triennial report (20012003) available on the CAPES website, the national agency of accreditation of graduate programs. From the list of publications of the 11 programs, a total of 5,628 publications were analyzed. The results suggest that the research in PE published by Graduate Programs has a limited visibility, since books and proceedings constitute the most 
frequent format. The results also show that publications with a biological approach, especially those based on physiology, are prominent, possibly an indication of the historical consolidation of the PE. Nevertheless, a strong influence of other disciplines is also evident, suggesting a remarkable epistemological heterogeneityin a fast and precise way, facilitating the analysis and assisting sailors and coaches on decision taking.

UnITERMS: Physical Education; Graduate programs; Research; Visibility; Multidisciplinary.

\section{Referências}

BETTI, M.Educação física escolar: do idealismo à pesquisa-ação. 2002. 336 f. Tese (Livre-Docência em Métodos e Técnicas de Pesquisa em Educação Física e Motricidade Humana) - Faculdade de Ciências, Universidade Estadual Paulista, Bauru, 2003. BETTI, M.; CARVALHO, Y.M.; DAOLIO, J.; PIRES, G.L. A avaliação da educação física em debate: implicações para a subárea pedagógica e sociocultural. Revista Brasileira de Pós-Graduação, Brasília, v.1, p.183-94, 2004.

BOURDIEU, P. O poder simbólico. 8. ed. Rio de Janeiro: Bertrand Brasil, 2005.

BRACHT, V. A constituição das teorias pedagógicas da educação física. Cadernos Cedes, Campinas, v.29, n.49, 1999.

Educação física e ciência: cenas de um casamento (in)feliz. 3. ed. Ijuí: Unijuí, 2007.

BRADFORD, S.C. Sources of information on specific subjects. Engineering, v.137, p.85-6, 1934.

CAMBI, F. História da pedagogia. São Paulo: Unesp, 1999.

COORDENAÇÃO DE APERFEIÇOAMENTO DE PESSOAL DE NÍVEL SUPERIOR (CAPES). Quesitos, indicadores e critérios para a avaliação trienal da grande área de ciências da saúde: 2001-2003. Disponível em: <http://www. capes.gov.br/images/stories/download/avaliacao/SaudeGrAreaCritAvaliacao2001_2003.pdf>. Acesso em: 24 nov. 2008.

Avaliação trienal 2007. <http://www.capes.gov.br/avaliacao/criterios-de-avaliacao/2284>. Acesso em: 27 mar. 2009.

KOKUBUN, E. Pós-graduação no Brasil: indicadores objetivos dos desafios e das perspectivas. Revista Brasileira de Ciências do Esporte, Campinas, v.24, n.2, p.9-26, 2003.

LOVISOLO, H. Pós-graduaçōes e educação física: paradoxos, tensões e diálogos. Revista Brasileira de Ciências do Esporte, Campinas, v.20, n.1, p.11-21, 1998.

Levantando o sarrafo ou dando tiro no pé: critérios de avaliação e qualis das pós-graduações em educação física.

Revista Brasileira de Ciências do Esporte, Campinas, v.29, n.1, p.23-33, 2007.

MARINHO, I.P. História geral da educação física. São Paulo: Cia. Brasil, 1980.

MECHIKOFF, R.A.; ESTES, S.G. A history and philosophy of sport and physical education: from ancient civilizations to the modern world. McGraw-Hill, 1998.

OLIVEIRA, V.M. Consenso e conflito da educação física brasileira. São Paulo: Papirus, 1994.

RAMOS, J.J. Os exercícios físicos na história e na arte: do homem primitivo aos nossos dias. São Paulo: IBRASA, 1983. ROSA, S., LETA, J. Tendências atuais da pesquisa brasileira em educação física. Parte 1: uma análise a partir de periódicos nacionais. Revista Brasileira de Educação Física e Esporte, São Paulo, v.24, n.1, p.121-34, 2010.

SOARES, C.L.; TAFFAREL, C.N.Z.; ESCOBAR, M.O. A educação física escolar na perspectiva do século XXI. In: MOREIRA, W.W. Educação física \& esportes: perspectivas para o século XXI. São Paulo: Papirus, 2005.

TANI, G. Educação física: por uma política de publicação visando à qualidade dos periódicos. Revista Brasileira de Ciências do Esporte, Campinas, v.29, n.1, p.9-22, 2007.

VERENGUER, R.C.G. Dimensões profissionais e acadêmicas da educação física no brasil: uma síntese das discussões. Revista Paulista de Educação Física, São Paulo, v.11, n.2, p.164-75, 1997.

ENDEREÇO

J acqueline Leta

Av. Brigadeiro Trompowisky, s/ $\mathrm{n}$

Prédio do CCS - Bloco B - sala 39

Cidade Universitária - Ilha do Fundão 21941-590 - Rio deJaneiro - RJ - BRASIL e-mail: jleta@bioqmed.ufrj.br
Recebido para publicação: 18/ 05/ 2009

Aceito: 30/06/2010 